\title{
memo: Official journal of the OeGHO and CECOG
}

\author{
Ulrich Jäger · Christoph C. Zielinski
}

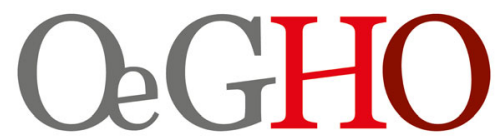

Österreichische Gesellschaft für Hämatologie \& Medizinische Onkologie

As Vice-President of the Austrian Society of Hematology and Medical Oncology, I have the pleasure and honor to congratulate memo on its 10-year anniversary. This international journal for oncology and hematology professionals now has an established role in the landscape of clinical hematology and oncology print media.

The Austrian Society of Hematology and Medical Oncology has adopted memo as its official journal for various reasons:

- It represents a platform for communication of important issues in the development of our field.

- A number of renowned Austrian hematologists and medical oncologists provide state-of-the-art information for practicing colleagues.

- Last but not least, it gives young researchers the possibility to publish their work in a frequently read journal.

Thus, it is not surprising that almost all members of the Editorial Board are members of the Austrian Society and of course the Editor-in-Chief has an important voice in the Scientific Board of the Austrian Society of Hematology and Medical Oncology. On occasion of the anniversary, one looks back with great content

\section{U. Jäger $(\bowtie)$}

Austrian Society of Hematology and Medical Oncology,

Vienna, Austria

ulrich.jaeger@meduniwien.ac.at

C. C. Zielinski, MD

CECOG, Vienna, Austria and I can only congratulate the editors for their outstanding work. Of course, there is always something to hope for. In this case, it would be desirable that the journal achieves a reasonable impact factor in order to make it even more attractive for national and international colleagues to publish their work and to give young colleagues the possibility to earn impact factors for their developing career. We all hope that memo will continue to thrive, and the Austrian Society of Hematology and Medical Oncology will support the journal wherever possible.

Congratulations and good luck for the next few decades!

\section{Ulrich Jäger}

Vice-President, Austrian Society of Hematology and Medical Oncology

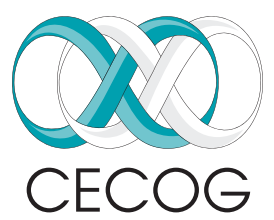

The entire community of the Central European Cooperative Oncology Group (CECOG), which has memo as its official journal, is very grateful to the journal and in particular to Prof. Wolfgang Hilbe as the Editor-inChief for the wonderful cooperation during the past 10 years. During this time, we have witnessed how memo has superbly developed and flourished, and we all hope for even bigger success in the future. But for now, we wish memo, its Editor-in-Chief, its Editorial Board, and all the coworkers who make the publication possible all the best for the 10-year anniversary of the journal.

Christoph C. Zielinski, MD

President, CECOG 